these laminæ which, acting as " films," give rise to all the colour of nacre, practically; and the phenomenon should be included amongst those of colours from "films," and not from "striated surfaces," the latter being merely incidental, and for all practical purposes contributing nothing to the effect.

\section{E. BENHAM.}

\section{A RATIONAL CURE FOR SNAKE-BITE.}

WHEN it was established beyond dispute or cavil that the serum obtained from animals, immunised against bacterial infections and intoxications, possesses in a marked degree antitoxic powers--as distinguished from antibiotic powers---and that such serum when mixed in a test-tube with the bacterial poison in question will, so to speak, neutralise the toxic effects of such poison, however deadly, it was merely a question of time, opportunity, and patience that attempts would be made to extend the principle of serum-immunisation to other, i.e. non-bacterial, poisons. Ehrlich was the first to show us the way. He gradually accustomed animals to withstand comparatively large doses of abrine, ricine, and robine, three vegetable toxines, all belonging to the group of proteines, reacting as albumoses or globulines. In that manner he produced in the animals a relative immunity, or perhaps, more correctly, a tolerance. $\mathrm{He}$ found that though subcutancous inoculations lead to better results, that this immunity can be brought about also by feeding. In whatever way the animal is prepared, its serum eventually acquires specific antitoxic, immunising, and curative properties. It was thus demonstrated that the wonderful discovery of Behring and Kitasato-for which Behring, however, claims the sole credit-has a scope much wider than at first was dreamt of. Behring himself, to begin with, explained the action of the serum as antibiotic or germicidal; but it soon became evident that, though when injected into the animal body it causes the destruction and death of the infective pathogenic organisms, nevertheless its chief action is "vitally" antitoxic. For working with the tetanus toxine alone, separated from the bacilli which produced it, its deadly effects can be readily neutralised by a few cubic centimetres of a powerful serum. And if we remember that 23 milligram of tetano-toxine would represent the fatal dose for a human being weighing 70 kilogrammes, then we can get an idea as to what extraordinary changes must have been produced in the serum, or rather in the blood and tissues, of the immunised animal, to enable its serum instantaneously to remove the lethal effect of the toxine. The only poison comparable to tetano-toxine in virulence and rapidity of action is cobra poison, and it also resembles chemically the bacterial toxines, reacting as an albumose, though for the sake of accuracy it must be mentioned, that the poison of tetanus has been clearly shown by Brieger, Cohn, and Sidney Martin not to be an albuminous body, and that possibly most of the bacterial toxines may turn out not to be albuminous substances. Still, so far as our present knowledge reaches, cobra poison and other snake venoms are chemically closely allied and analogous to the "toxalbumins" of bacteria.

It had also been demonstrated by several observers, ${ }^{1}$ that by means of oft-repeated injections of small sublethal doses of snake poison (rattlesnake, cobra, or viper venom) the resistance of an animal against the poison may gradually be increased considerably, it may be rendered "giftfest," to borrow a German expression. In fact, all the methods used for inducing a tolerance against tetanus poison can be shown to work in the case of cobra poison (this is the poison generally employed). Thus Calmette, whose work in this line follows directly

1 Sewall, Journal of Physiology; Kanthack, ibid., 1892, vol. xvi. Nos. 3 and 4 ; Phisalix et Bertrand, Compt. rend. de l Acad. d. sc. cxviii. 1894 , pp. 288,356 ; A rch. de physiol. 5 sér. vi. 3 , 1894, pp. $567,6 \mathrm{II}_{\mathrm{I}}$; Compt. rend. de la soc. d. biol. 9 sér. vi., 1894, pp. 11 1 , I24; Kaufmann, ibid., p. rr3,
and Calmette, Annales de l'Inst. Past. 1894, vol. viii. No. 5, p. 28r.

NO. I 356 , VOL. 52$]$ that of Sewall's and of the writer of this article, has shown that a so-called immunity can also be produced by gradually increasing injections of poison attenuated by heat, iodine, trichloride of iodine, hypochloride of calcium, $\& c$; in fact, the analogy is complete. From this stage, at which others had already arrived, Calmette went ahead with Phisalix and Bertrand. Having previously attempted both to prevent and to cure the effects of inoculation with cobra poison by means of chloride of gold - wherein, however, as shown by the writer, ${ }^{1}$ he failed-he directed his attention at once to the serum of immunised animals, and in February 1894 he showed, before the Société de Biologie, that on mixing cobra or viper venom with small quantities of serum obtained from an immunised rabbit the deadly effect of the venom disappears, a fact at once confirmed by independent observations of Phisalix and Bertrand. In May 1894 and in April i 895, Calmette published two concise papers in Pasteur's Annales, containing a full account of his results. These, briefly summarised, are as follows: (I) The serum of an animal immunised against snake poison (he used poisons of the following snakes: Naja tripudians and haje, Crotulus durissus, Bothrops lanceolatus, Cerastes, Pseudechis porphyriacus, Hoplocephalus curtis and variegatus, Acanthopis antarctica, Trimeresurus viridis) possesses properties similar to those which the serum of animals immunised against tetanus and diphtheria possesses. (2) The serum of a rabbit immunised against cobra or viper venom acts equally well against any of the other poisons, i.e. there is no specificity of action, as judged by the species of snake. (3) The serum possesses not only neutralising properties when mixed with the venom in a test-tube, but possesses also marked immunising and curative properties, i.e. poison injected after previous serum administration becomes powerless, and serum injected after previous poison administration neutralises the effects of the poison in the animal body, even after the symptoms of intoxication have already set in. Naturally the effect depends on the degree of imnunity of the serum giver and on the proportionate amount of serum used. (4) The immunising effect produced by serum injections is not so lasting as that produced by direct injections of the poison, i.e. serum injections are incapable of rendering animals "giftfest." Calmette alludes to other matters, but since these are of secondary importance and still debatable, and not directly related to the subject of this article, we must pass them over. There is, however, one point which must be inentioned, since it is one affecting the whole principle of serum immunisation. He states that he has succeeded in producing a "Giftfestigkeit" by means of repeated intravenous injections of hypochloride of calcium, and that the serum of such "chlorinated" animals will neutralise, in the test-tube at least, the effects of cobra poison. Roux elsewhere mentions ${ }^{2}$ that the serum of animals immunised against tetanus or rabies is capable of neutralising snake venom and of protecting other animals against subsequent intoxication with cobra poison, and that rabbits vaccinated against rabies can withstand four to five times the lethal dose of cobra venom; and also that abrine serum will counteract the effects of cobra poison, and cobra serum those of abrine. Calmette goes so far as to say that an animal vaccinated against abrine may acquire a relative immunity against diphtheria, ricine, and anthrax. If this be so, we shall have to modify our views as to the specific action of antitoxic serum, i.e. the first principle of serum therapeutics. We require a number of control observations before we can accept these remarkable statements; partial contradiction they have already received from Germany, ${ }^{3}$ and the

\footnotetext{
1 Lancet, June 11,1892 . The uselessness of strychnine was previously demonstrated by the writer in his paper in the Journal of Physiology.

2 Annales de l' Inst. Past. r894, No. 10, p. 722. to abrine and ricine (cf. Deutsche Med. Wochenschrift, vol wiit ro regard
} p. 1218). 
writer's own experiments, so far at least, do not lend much support to them. So long, however, as the whole question of this new treatment, striking though it is in its results, is still a mystery to us, we cannot afford to push aside observations because they seem improbable, or because they are contradictory.

Calmette asserts also that the fresh serum of Naja tripudians (a species of cobra) possesses to some degree at least immunising properties, and, as we shall see, Fraser ${ }^{1}$ bears him out in this, by stating that fresh serum of poisonous snakes possesses strong antitoxic and protective properties, not only against their own venom, but also against that of other species. D. D. Cunningham ${ }^{2}$ and the writer, ${ }^{3}$ however, in India, invariably failed to obtain antitoxic or immunising effects with cobra blood or serum, although the writer succeeded in keeping the effects of cobra poison in abeyance by means of the blood (or serum) of the Varanus Bengalensis, a large lizard which is naturally strongly resistant against cobra poison.

These are the chief results obtained by Calmette, and knowing the difficulties of working with such deadly poison as cobra poison venom is, and the innumerable failures which accompany it, the writer is able to appreciate the success of the French author, all the more since he himself failed while working on the same lines where to succeed seemed simply a matter of course. Recently these French observations have received entire confirmation in their leading points by Prof. Fraser of Edinburgh, and the writer may be forgiven for stating here that though he took up the control of Calmette's work with strong bias against the latter, he felt himself forced, already before Fraser's communications appeared, to acknowledge the correctness of the work done at Pasteur's Institute, so far as the antitoxic and immunising properties against cobra poison of serum obtained from animals treated with that poison are concerned. He has not, however, convinced himself that hypochloride of calcium can immunise animals, or lead to the formation of an antitoxic serum. Fraser's contributions, though merely confirmatory, are of great importance, since they contain unquestionable proof of the truth of what must have appeared to all, except a few shrieking "zoophilists," to be striking and surprising revelations. The credit, however, of the discovery of a cure for snake-bite-in the laboratory at least-belongs solely to France. Having discussed Calmette's work more fully, we can speak of Fraser's experiments in a few words; but thereby we do not wish to detract in any way from the merit which characterises his researches.

Fraser ${ }^{4}$ worked with venom obtained from the Indian cobra, thrce species of rattlesnakes (Crotalus horridus, $C$. adamanteus, and $C$. durissus), the copper-head (Trigonocephalus contortrix), the Australian black and brown snakes, and an unidentified Diemenia (Pseudechis porphyriacus and Diemenia superciliosa), the African puff-adder night adder, yellow cobra, and "rinkas" (Vipera arietans, Aspidelaps lubricus, Naja haje, Sepedon hamachates). He immunised his animals by the usual method of minimal subcutaneous inoculations, or by feeding, against the venoms of some of the snakes mentioned, and then established (a) the strong specific antidotal properties of the serum of these vaccinated animals against the poison with which they had been vaccinated, and $(b)$ the vicarious antidotal properties against the other poisons. This serum he obtained in a dry, pulverisable condition without any appreciable loss of antidotal power ; but we can hardly forgive him the hybrid and barbaric name "antivenene" which he applies to it. He confirms Calmette's results in almost every point, so that there is no longer

1 Lancet, August xo, 1895, p. 376, and Brit. Med. Journal, Aug. 17, 1895. 2 Private communication.

3 Journal of Physiology, 1892 , vol. xiii. Nos. 3 and 4, p. 288.

4 British Medical Journal, I895, June 15, p. I309-1312. NO. I 356 , VOL. 527 any doubt left as to possibility of a successful cure against snakebite, especially as, by both observers, the curative injection was shown to be efficacious when the symptoms of intoxication had already set in, and as the experimental animals used were highly susceptible to the poisonous action of serpents'venoms, while man is weight for weight much less sensitive than a guinea-pig or a rabbit. True, Fraser has generally worked with comparatively small lethal doses ; this possible objection is, however, met by Calmette's results, which were obtained with much larger doses, and which therefore allow us to judge favourably of the practical application of the serum treatment. The final verdict must, of course, depend on the success or failure following the use of the serum in cases of snake-bite, and it must be remembered that, striking though our laboratory results are with tetanus antitoxine, so far the success obtained with acute cases of tetanus in man is disappointingly small, as the writer has shown elsewhere. ${ }^{1}$ Yet here we have a rational method of treatment, and the promise of almost certain success; we must now look for facilities and opportunities of trying the cure. In France they have already begun to manufacture this antitoxic serum in larger quantity, and Calmette writes that he has immunised a horse, and is ready to supply the remedy; and Fraser also has larger animals under treatment. No doubt India will not delay in carrying out the necessary arrangements for procuring what, after all, will be an imperial benefit.

The vicarious action of the immunising venom-serum is surprising, and may find an explanation in the similarity of the physiological action of the various poisons used. They are all poisons which cause death by acting on the central nervous system, especially the medulla, the animal dying from respiratory failure with salivation, retching, $\& c$. And it is quite possible that chemically similar poisons which, according to their action on the animal body, belong to one physiological group, have the same antidote. It would therefore be interesting to test the antitoxic cobraserum on the poison of the Daboia, which, according to Wall, Cunningham, and others, differs essentially in its physiological action ; for whereas cobra, crotalus, and viper venoms are paralysing, medullary poisons, the poison of Russell's viper produces very varying symptoms, in some cases convulsions, in others paralysis and asphyxia, in yet others violent convulsions followed by paralysis. Daboia venom undoubtedly contains a substance capable of producing the most violent convulsions, especially in birds, their occurrence depending on the size of the animal and on the amount of poison injected. It would indeed be more than a surprising revelation, if a serum which is capable of acting as an antidote to a paralysing toxine were also capable of neutralising the effects of a toxine of opposite physiological action.

The vicarious antidotal action of venom-serum must appear all the stranger and more contradictory if we remember that not all poisonous snakes are "giftfest" against the poisons of other different species. Waddell " has shown that the venom is neither a poison to the snake itself nor to members of its own species, but that cobra poison is fatal to some, if not perhaps to all, poisonous snakes. It will certainly kill the Trimeresurus erythrurus, and in the writer's experience also the crotalus, while according to Fayrer the Bungarus readily falls a victim to the bite of a cobra. This being so, why should the antitoxic serum of an animal immunised against cobra-poison be active against rattlesnake venom, when in an experiment recently performed by the writer, a strong and healthy crotalus succumbed to five milligrammes of cobra venom? Lastly some writers, Fraser included, assume that the immunity of poisonous snakes against their own

1 Medical Chronicle, May 1895

2 "Scientific Memoirs by Medical Officers of the Army of India," I 889 , iv. p. 59 . 
poison depends on self-immunisation, called forth by swallowing their own venom, or by repeatedly inoculating themselves. This is highly improbable, if we remember that some of the innocent snakes are very resistant against cobra poison, as, c.g., the Ptyas mucosus and the Tropidonotus natrix, and also that, as the writer has shown the Varanus Bengalensis is possessed of a marked tolerance, and that, according to Fayrer, other species of Varanus survive the bite of a cobra 24 to 48 hours. Jourdain further gives a list of four innocent snakes which are immune against viper venom. In what manner are we to account for this immunity? Interesting observations on the poisonous nature of serum of innocent and poisonous snakes are also found in Calmette's paper of April I895, which, while rendering Fraser's theory still more improbable, do not assist us in clearing up the mystery. The explanation must be left to future researches; for the present we must be thankful for the promise which the researches of Calmette and Fraser have given us, of allaying an almost national calamity.

\section{A. A. K.}

\section{SCIENTIFIC KNOWEEDGE OF THE} ANCIENT CHINESE.

THE question of China has been so much to the front lately, that an article which appeared in one of the August numbers of the Fierue Scientifique, on the knowledge of science possessed by the Chinese, seems very $a$ propos. It cannot be denied that the Chinese of the present day have very elementary ideas on any branch of science. This however, was not so formerly.

In early times, as far back even as 2000 B.C., we find that science in China had reached a fairly advanced stage. The Chinese possessed undoubtedly a great knowledge of astronomy ; inscriptions have been found which prove this. In the "Chou-King," a book of records, we read that Emperor Yao, who reigned 2357 B.C., did much to advance the study of this science. He ordered his astronomers to observe the movements of the sun, moon and stars, and showed them how to find out the commencement of the four seasons by means of certain stars. We read also that he told them that a year consisted of a little less than 366 days, and as he divided the year into lunar months, he taught them the years in which the additional lunar month ought to be included. It is also known that the Chinese had the annual calendar, that they observed the planets Mercury, Venus, Mars, Jupiter, Saturn, and were able to calculate eclipses, and knew the difference between the equator and the ecliptic. It is quite probable that the ecliptic was not known of before the Mussulmans occupied the Mathematical Tribunal, which they held for three centuries.

We see, therefore, that the knowledge of astronomy was very extensive. With regard to the meridian, it was apparently unknown to them. M. Chavannes, who is at present Professor of Chinese at the College of France, says that it is not mentioned in any astronomical book. As substitute a certain star was observed at the same hour, according to the times of the year, note being taken of its positions with regard to the horizon.

Astronomy has always been closely connected with astrology. By means of astronomy the time was ascertained for the numerous public ceremonies recorded in the Imperial calendar; it likewise regulated the affairs of the Government. But the calendar has long since ceased to be used for this latter purpose, and the majority of the Chinese population merely look upon it as a means of continuing the mysterious ceremonies and oracles connected with the different positions of the planets. It is ordered in the "Collection of the Laws," that at each eclipse, ceremonies should be gone through to deliver the eclipsed sun or moon. At this time there- fore, an alarm is sounded on the drums, the mandarins arrive armed, utter many objurgations, and thus deliver the endangered bodies.

In the seventeenth century, certain Jesuit missionaries arrived in China. On seeing the low state into which the Mathematical Tribunal had fallen, they offered to help it. They found an observatory containing many instruments, which shows plainly that this branch of science had at one time reached an advanced stage. This decay of science is not to be wondered at when we remember that twenty-two dynasties were brought on the throne by actual revolutions. Nor is this decay confined to astronomy. According to the ancient books and traditions, we find that various branches of science had reached a high degree of culture.

The Emperor Kang-hi, who reigned in the seventeenth century, had a great love of study himself, and endeavoured to advance the general education in China. The Jesuit missionaries instructed him in geometry and physics. He translated some text-books into Chinese.

The Chinese have generally been credited with the invention of gunpowder. A certain document has been found, however, by Archimandrite Palladius, a Russian sinologue, stating that in the ninth century a Persian regiment, under the Chinese sovereign, made known a material similar to wild fire, which was afterwards used for fireworks.

Apparently, chemistry has never been studied, unless by a certain sect, the Tao-tse, who spent all their time endeavouring to discover the philosopher's stone and the elixir of life.

The Chinese have not a great knowledge of geology. The mines have been worked without any machinery, and are not very deep, therefore fire-damp has rarely been the cause of destruction. Coal was extracted at as early time as 200 B.C. in the dynasty of Han. Although the mode of extraction was very primitive, enough was obtained to satisfy all wants.

About 1861 the Government handed the exploration of the mines over to American prospectors. The work, lasting from I 862-64, was directed by Prof. Pumpelli, who at its termination sent the Emperor a report and a map of the coal-fields. The Smithsonian Institute of Washington have had these documents published; they have also appeared in the diplomatic correspondence of the United States (1864). Later on, Baron de Richtofen did similar work, and found that the coal-fields in China are even more extensive than those in North America.

Research work has not been carried far in natural science. In zoology their classifications are quite wrong. The drawings in zoological and botanical books can often scarcely be recognised. Their most ancient work on botany dates from 2700 B.C., and is a treatise written by the Emperor Shen-nung; it is merely enumerative. Another work, the "Rh-ya," dates from I200 B.C., and shows signs of progress. The "Pen-tsao," an encyclopedia, is, according to M. Bretschneider, of little value.

This Russian investigator speaks of the Chinese as follows: "It is an undeniable fact that the Chinese do not know how to observe, and have no regard for truth ; their style is negligent, full of ambiguities and contradictions teeming with marvellous and childish digressions."

However, in a more recent communication, M. Bretschneider retracts his words, and says that it is more that the Chinese will not observe, than that they cannot, for Lichi-Tchen, author of several interesting pamphlets, brings forward many facts concerning cultivated plants.

With regard to medical science, it is very elementary. Occasionally here and there a successful doctor is to be found. This lack of knowledge is not to be wondered at, for Buddhism forbids dissection of bodies. In the temple of Confucius a bronze figure is to be found, on which all the different parts are marked where the surgical needle

$$
\text { NO. I } 356 \text {, VOL. } 52 \text { ] }
$$

